\title{
Studying the effects of fish muscle incorporation on storage stability of a novel corn-fish snack
}

\begin{abstract}
To investigate the effect of minced fish incorporation on storage stability of a puffed cornfish snack, treatments including 15\% silver carp (Hypophthalmichthys molitrix) meat and $85 \%$ corn (seasoned and unseasoned) were produced by a twin screw extruder. The peroxide values (PVs) of treatments increased (P值l.05) with storage time and reached a peak in the 12th week, then the values declined following a quadratic model. The fish was the least significant factor (P $\mathrm{AlOL}$ 05), meaning that incorporation of minced fish slightly affected the PV. Conversely, the seasoning was the most significant factor (P time. The total volatile base nitrogen and free fatty acid concentration of treatments increased linearly during storage. No significant difference (P\\0.05) was found for crispiness and color. Also, no microbial growth was observed during storage. The storage stability of the seasoned corn-fish snack and the control was obtained 28 and 33 weeks, respectively.
\end{abstract}

Keyword: Corn-fish snack; Storage; Minced fish 